First Peoples Child \& Family Review

A Journal on Innovation and Best Practices in Aboriginal Child Welfare Administration,

Research, Policy \& Practice

\title{
A Commentary on Alternative Approaches to the Research Process with Canadian First Nation Communities
}

\section{Doreen Stevens}

Volume 3, Number 2, 2007

Special Issue: Adolescent development, mental health, and promising research directions for Aboriginal youth

URI: https://id.erudit.org/iderudit/1069462ar

DOI: https://doi.org/10.7202/1069462ar

See table of contents

Publisher(s)

First Nations Child and Family Caring Society of Canada

ISSN

1708-489X (print)

2293-6610 (digital)

Explore this journal

Cite this document

Stevens, D. (2007). A Commentary on Alternative Approaches to the Research Process with Canadian First Nation Communities. First Peoples Child \& Family Review, 3(2), 50-51. https://doi.org/10.7202/1069462ar viewed online.

https://apropos.erudit.org/en/users/policy-on-use/ 


\section{A Commentary on Alternative Approaches to the Research Process with Canadian First Nation Communities}

\section{Doreen Stevens ${ }^{\mathrm{a}}$}

${ }^{a}$ Department of Psychology, Mount Saint Vincent University, Halifax, NS, Canada

As a co-investigator of one of the research studies in this issue(Building a Collaborative Understanding of Pathways to Adolescent Alcohol Misuse in a Mi'kmaq Community, p. 27), I have had a unique opportunity to work in a multiple capacity roles. In addition to being a community member and a research partner, I am also a graduate student in school psychology. My submission is intended to share my experiences in my capacity role as a First Nation support worker, particularly in research, with the hope of providing some guiding principles and practices when conducting research in a First Nation community. Based on my experience in conducting research on First Nation mental health issues, it seems oftentimes lacking in publications in scholarly journals. This makes it difficult when looking for sources for information. There could be a number of reasons for the deficiency in published information on First Nation issues. In my experience in consultation with community members, their initial reaction is "we have been studied to death", or "researchers from outside the community come in and take information to use for their own benefit", or "what do we get out of it?". While all these responses might be accurate on some level, it leads me to the question as to why it seems so difficult to find information on First Nation issues especially in Canada.

Some possibilities as to why it is difficult to find information on First Nation issues, especially in psychological research, might be that the nature of psychology can conflict with many First Nation sociocultural principles. It has been, at times, challenging to apply many of the principles in psychology in my practice as a guidance counselor working with my Mi'kmaq speaking First Nation community. I often have difficulty in the application of psychological theories and principles as they originate typically from European scientists which often clash at least in part with the Aboriginal worldview. In my practice, more often than not, psychological methods require adaptation to fit the circumstance. Since, the arrival of Europeans and the colonization of the First Peoples of this country, there is a residual sense of distrust of Europeans by many First Nation community members. This sense of skepticism has potential to interfere with the process of conducting a research study such as the one I am co-investigating. As a service provider, the valuable information this study has to offer is recognized as beneficial in developing programs to meet the anticipated needs based on the outcomes and recommendations the study provides. Recognizing the potential benefits of the study and hoping the community will consent to accepting its proposal is an example of the conflict experienced by a researcher from the community.

This study focuses on youth experiences and its effects on their current functioning. This information has possible clinical benefits by self reporting anonymously; this might be the first step to a full disclosure leading to therapeutic intervention. The nature of some items on the questionnaire can be perceived as highly sensitive and, therefore, community members might want to naturally protect the youth from exposure to some of the questions. A lot of time and rapport building is required in working 
toward obtaining consent to conduct a study of this nature.

My community is the largest Mi'kmaq community in the Atlantic region in size, population, and in Mi'kmaq speakers. The community is respectively rich in culture, language, and history. For a prospective researcher to go into the community intending to extract information from the community, he/she might be faced with a challenging task - one that requires as much consultation with community members as possible. For this particular study, the process was accelerated via community organizations. This particular community has organized committees whose members represent various stakeholders in the community, such as case management team, interagency committee, and the community health board. (Note: All these committees comprise of community members who meet and collaborate on concerning issues and/or developing interests about the community.) Many committee members are appointed by their supervisors to act on their behalf and report information back to their organization. Not all First Nation communities have active committees or boards; therefore, a researcher might have to meet with representatives individually rather than in groups. The research process may require variation in methodology based on the community and its needs. The planning and preparation is time-consuming, but an essential aspect of the research process. It is helpful when the researcher is able to follow and adapt to the timing of the community schedule. This part of the process may require months or even more depending on the community's reception of the proposed study. Allocation of more time gives the community members time to become familiar with the researcher, time to process the proposed study, time to ask questions, consult and make queries. In making initial contact, it depends upon the nature of the study and the target population. For instance, the target population of this study is the youth; the best access to youth is through the school. Therefore, the initial contact person for consent would be the director of education. If consent is obtained at that level, technically a researcher can then collect data, but may risk obtaining an insignificant number of participant consents and/or parental consents. The next stage is to make presentations to community committees by contacting the chairperson of each committee and consulting with them about how best to present information to that group. Often, it is better when the presentation is less formal, minimizing the length of the presentation and using less jargon where possible. This is also applicable to handouts: less is more. Allowing for more discussion time would likely be helpful in facilitating the process. For optimal results, these stages of consultation are recommended to get as many community members on board even before obtaining parental and participant consents. With our study, prior to data collection, the participating schools made presentations to the teaching staff and students about the proposed study and letters were sent home to parents so that as many individuals are aware about the study. After the data is collected and results are analyzed, as a best practice, the researcher is recommended to return to the community to disseminate the results to the committees and consultants of the community. In an effort to improving the research process in First Nation Communities, allowance for time is definitely recommended and consult, consult, consult.

Taking the time to go through the process as mentioned before could take several months which might lead to difficulties in meeting deadlines with university timetables. Perhaps, cultural awareness presentations could be developed and made available to participating universities interested in conducting research within First Nation communities. Another possibility might be to invite researchers experienced in conducting research in First Nation communities to develop a paper on guiding principles and made available online as a link on university websites. As a frontline worker in my community, I look forward to seeing more scholarly research conducted with Aboriginal people in Canada especially in the mental health field making information about our people relevant, practical, and meaningful. 